\title{
How the Left-periphery of a $W h$-relative Clause Determines Its Syntactic and Semantic Relationships
}

\author{
Anke Holler \\ Ruprecht-Karls-Universität Heidelberg \\ holler@cl.uni-heidelberg.de
}

\begin{abstract}
This paper discusses a certain class of German relative clauses which are characterized by a $w h$-expression overtly realized at the left periphery of the clause. While investigating empirical and theoretical issues regarding this class of relatives, it argues that a $w h$-relative clause relates syntactically to a functionally complete sentential projection and semantically to entities of various kinds that are abstracted from the matrix clause. What is shown is that this grammatical behaviour clearly can be attributed to the properties of the elements positioned at the left of a $w h$-relative clause. Finally, a lexically-based analysis couched in the framework of HPSG is given that accounts for the data presented.
\end{abstract}

\section{Introduction}

This paper concentrates on German relative clauses introduced by a $w h$-expression and therefore called ' $w h$-relatives'. A typical example of a $w h$-relative clause is given in (1):

(1) Anna hat die Schachpartie gewonnen, was Peter ärgerte. Anna has the game of chess won which Peter annoyed

'Anna won the game of chess, which annoyed Peter.'

The investigation of the $w h$-relative clauses is worthwhile for three reasons. First, $w h$-relatives are syntactically peculiar as they show characteristics of both, root and subordinate clauses. Second, $w h$-relatives matter semantically as they can be related to different semantic entities contained in the matrix clause. This relationship is only restricted by the semantic type of the leftperipheral $w h$-expression. Third, although $w h$-relatives are mentioned in almost every grammar book of German, to date their grammatical properties have not been studied comprehensively, the only exception being Brandt (1990). Brandt, however, focusses on the pragmatic aspects of the $w h$-relative construction and therefore a formalized syntactic and semantic analysis of the $w h$-relatives is still missing.

The paper is organized as follows. In sections 2 and 3, it will be argued that the assumption common in the philological literature that $w h$-relatives are generally sentence-related is incorrect. In section 2 , it will be shown that the 
antecedent of a $w h$-relative is sentential only with respect to its syntax. Semantically, however, a wh-relative potentially can refer to any entity that can be abstracted from the preceding syntactic string. In section 3, it is argued that this relationship is only restricted by the semantic type of a $w h$-anapher introducing the relative clause.

Section 4 will further investigate the syntactic behaviour of wh-relative clauses - in particular, how wh-relatives are linked to the complex sentence structure. It will be argued that a $w h$-relative is a typical non-integrated clause, which can be attributed to the properties of a phonologically empty relativizer that serves as the head of a $w h$-relative.

In section 5, an HPSG analysis will be developed that gives an adequate formalization of the data presented. Section 6 will conclude the paper.

\section{$2 \quad$ Are $W h$-Relatives Sentence-related?}

In the philological literature (see Helbig 1980, among others) it is stated that $w h$-relatives are generally sentence- or fact-related. It is assumed that the complete matrix clause is the syntactic and semantic antecedent of the left-peripheral $w h$-expression introducing the $w h$-relative clause. However, it can be shown that wh-relative clauses should be considered sentence-related only with respect to their syntax, since they can be related semantically to various kinds of abstract entities. The anaphoric $w h$-expression introducing the $w h$-relative clause determines the semantic type of this abstract object.

\subsection{Overt Left-peripheral Expressions}

Three kinds of expressions which may act as a complement or an adjunct of the relative clause's predicate can be observed on the left of a wh-relative. The first is the underspecified pronoun was ('which'), as illustrated in (2). Was represents either a verbal phrase or a nominal phrase. In the latter case was is not specified with respect to person, number and gender, but depending on the selection properties of the respective predicate, it is case-marked as nominative or accusative.

(2) a. Max kann Orgel spielen, was ${ }_{V P}$ Anna auch kann.

Max can organ play which Anna too can

'Max can play the organ, which Anna can, too.'

b. Max spielt Orgel, was ${ }_{N P[N O M]}$ gut klingt.

Max plays organ which good sounds

'Max is playing the organ, which sounds good.' 
c. Max spielt Orgel, was ${ }_{N P[A C C]}$ Anna überrascht.

Max plays organ which Anna surprises

'Max is playing the organ, which surprises Anna.'

The second kind of expression is wh-adverbs such as weswegen ('why') and wofür ('for which'), as illustrated in (3). These adverbs preserve their modal, temporal or causal meaning if they occur in a $w h$-relative.

(3) a. Otto hat sich sein Bein gebrochen, weswegen er jetzt im Otto has REFL his leg broken that's why he now in Krankenhaus ist. hospital is

'Otto broke his leg, and that's why he is in hospital now.'

b. Otto schenkt Emma Schokolade, wofür sie ihm dankt. Otto gives Emma chocolate for which she him thanks 'Otto gives Emma chocolate for which she thanks him.'

The third kind of expression is complex expressions including a wh-element and an abstract noun as exemplified in (4). In this case, the meaning of the abstract noun has to be compatible with the meaning of the matrix clause's predicate.

(4) Max bat Maria, einen Brief einzuwerfen, welcher Bitte sie Max asked Maria a letter to mail which request she nachkam.

granted

'Max asked Maria to mail a letter, and she granted this request.'

\subsection{Variants of the Wh-relative Construction}

It is generally agreed that $w h$-relatives can be considered relative clauses: they are attached to a preceding clause and they are introduced by a $w h$-relative constituent that is grammatically dependent on the predicate of the $w h$-relative and linked to an element in the matrix clause. Depending on the syntactic status of the $w h$-expression three $w h$-relative construction variants can be distinguished, which are referred to 'variant A', 'variant B' and 'variant C'. In the construction variants $\mathrm{A}$ and $\mathrm{B}$, the left-peripheral $w h$-expression is selected by the relative clause's predicate. In the construction variant $\mathrm{C}$, the wh-expression modifies the respective predicate.

The sentence given in (1) is an example for the variant A construction. Predicates that occur in a $w h$-relative of this variant are subcategorized for a finite sentential or an infinitival complement of the '2. Status' (Bech 1957) that can alternatively be realized as a nominal or prepositional phrase. For this reason a verb like sich weigern 'to refuse to do something' cannot occur in a $w h$-relative, 
as can be seen in (5). Although sich weigern allows an infinitival complement, as shown in (5b), it cannot take a nominal complement, as shown in (5c).

(5) a. * Peter soll seinen Freund verraten, was er sich weigerte. Peter was to his friend betray which he REFL refused

'Peter was to betray his friend, but he refused it.'

b. Peter weigerte sich, seinen Freund zu verraten.

Peter refused REFL his friend to betray

'Peter refused to betray his friend.'

c. * Peter weigerte sich den Verrat seines Freundes.

Peter refused REFL the betrayal his friend

Examples of the variant B construction are given in (6). This construction variant is similar to VP-ellipsis, as was 'which' realizes a VP complement. The class of verbs occurring in these constructions is restricted to auxiliary verbs such as haben 'to have', sein 'to be' and werden 'will' and to auxiliary modal verbs with root interpretations. Hence, example (7) containing an epistemic modal is ungrammatical.

(6) a. In München hat es geschneit, was es in Stuttgart auch In Munich has EXPL snowed which EXPL in Stuttgart as well hat.

has

'It snowed in Munich and in Stuttgart as well.'

b. Otto muss nach Frankreich fahren, was Max jetzt auch soll.

Otto must to France go which Max now too should

'Otto must go to France, which Max should do now, too.'

(7) * Peter muss krank gewesen sein, was Otto auch muss. Peter must sick been has which Otto too must.

As mentioned before, variant $\mathrm{C}$ construction covers all clauses introduced by a $w h$-phrase modifying the $w h$-relative's predicate. This is exemplified in (8):

(8) Otto ist krank, weshalb er zu Hause bleiben muss.

Otto is sick that's why he at home stay must

'Otto is sick, and that's why he has to stay at home.'

The construction variants also differ semantically, since the antecedent of a $w h$ relative depends on the semantic properties of the respective $w h$-expression. This issue will be discussed in the following sections. 


\subsection{The Antecedent of a $W h$-relative}

In the literature on $w h$-relatives one mostly finds the statement that a $w h$-relative is sentence-related. Based on the assumption that the matrix clause of the $w h$-relative construction can be transformed into a component of the relative clause, ${ }^{1}$ it is claimed that a $w h$-relative and its matrix clause establish an inverse dependency relation. Assuming this inverse relationship, the $w h$-expression is taken as a place holder or a variable representing the whole matrix clause, as is done, for instance, by Helbig (1980) and Steube (1991).

Contrary to this assumption, Brandt (1990) argues that examples like (9) show that $w h$-relatives can be related to sub-sentential syntactic units, too.

(9) Er kann schon schwimmen, was sie noch nicht kann. He is able to already swim which she yet not is able to

'He is able to swim, which she isn't, yet.'

However, the phenomenon she describes cannot be attributed solely to syntax. As suggested by example (10), the data should instead be explained in semantic terms.

(10) a. Die Geologen erforschen einen neuen Vulkan, was sehr the geologists explore a new volcano which very interessant ist.

interesting is

'The geologists explore a new volcano, which is very interesting.'

b. Dass sie einen neuen Vulkan erforschen, ist sehr interessant.

'That the geologists explore a new volcano is very interesting.'

c. Einen neuen Vulkan zu erforschen ist sehr interessant.

'To explore a new volcano is very interesting.'

d. Das Erforschen eines neuen Vulkans ist sehr interessant.

'The exploring of a new volcano is very interesting.'

Depending on the interpretation of the wh-anaphor, (10a) has three readings, (10b) - (10d). Was ('which') can be resolved (i) by the proposition denoted by the matrix clause, as in reading (10b); or (ii) by an event-type such as the process of exploring, as in reading (10c); or (iii) by the exploration-event, as in reading (10d). Because the string of the matrix clause standing alone is not ambiguous at all, examples like (10) prove that the crucial grammatical relation between a $w h$-relative and its matrix clause is a semantic one. This view is also supported by the data given in (11).

(11) a. Maria will sich ihre Haare kämmen, was Hans auch will. Maria wants REFL her hair comb which Hans too wants 'Maria wants to comb her hair, which Hans wants to do, too.'

\footnotetext{
${ }^{1}$ In the German grammar tradition, the term Satzglied is used here.
} 
b. Hans ${ }_{i}$ will $\operatorname{sich}_{i}$ seine Haare kämmen.

'Hans wants to comb his hair.'

(11a) has a reading where the reflexive pronoun sich 'herself' / 'himself' gets a sloppy interpretation, as expressed by (11b). This reading could not be explained by a syntactic operation that just transforms parts of the matrix clause into a component part of the $w h$-relative.

The semantic nature of the reference relation is further substantiated by (12). The indefinite NP in the matrix clause is interpreted generically, whereas it gets a specific interpretation within the $w h$-relative. Thus, the semantic information of the matrix clause is accessible from the $w h$-relative clause.

(12) Maria wollte keinen Linguisten heiraten, was sie dann aber doch Maria wanted no linguist marry which she then PART PART getan hat. done has

'Maria didn't want to marry a linguist, which she did in the end.'

Consequently, one must strictly distinguish between the syntactic and the semantic relations established within the $w h$-relative construction: whereas the semantic relation is triggered by the left-peripheral $w h$-anaphor, the syntactic relation affects the way the $w h$-relative is attached to its preceding clause. As will be shown later, this is controlled by a phonologically empty relativizer heading the $w h$-relative clause. Beforehand the semantic relationship between the $w h$-anapher and its antecedent will be further investigated.

\section{Semantic Aspects}

It is generally claimed that a $w h$-relative must refer to a fact. This claim is incorrect. A reference to facts is indeed possible, as (13) shows:

(13) Grass sagte die Lesung ab, was bedauerlich ist. Grass cancelled the reading $\mathrm{PART}$ which regrettable is

'Grass cancelled the reading, which is regrettable.'

However, the example in (10) and the ones in (14) below indicate that a whrelative refers to non-propositional entities as well, since the left-peripheral $w h$ anaphor can be related to entities of various semantic types.

(14) a. Nachbars Hund bellte, was sogar Anna hörte, obwohl sie zwei neighbor's dog barked which even Anna heard although she two Straßen weiter wohnt. blocks away lives

'The neighbor's dog barked, which even Anna heard although she lives two blocks away.' 
b. Max rasierte sich, was eine halbe Stunde dauerte. Max shaved REFL which an half hour took 'Max shaved, which took him half an hour.'

c. Anna gewinnt immer die Schachpartie, was Peter ärgert. Anna wins always the game of chess which Peter annoys 'Anna always wins the game of chess, which annoys Peter.'

d. Karl hat den K2 bestiegen, was Otto auch gelungen ist. Karl has the K2 climbed which Otto as well achieved is 'Karl climbed the K2, which Otto achieved as well.'

In (14a), the predicate of the $w h$-relative consists of a recognition verb, namely hören 'to hear', and the wh-anaphor was 'which' refers to the event of a dog barking. Similarly, the $w h$-anaphor in (14b) restricted by the verb dauern 'to last' refers to an event. (14c) and (14d) show once more that event-types are possible antecedents of a $w h$-relative. (14c) means that Peter is annoyed every time Anna wins the game of chess. The verb gelingen 'to achieve' in (14d) generally selects an event-type if the respective argument is verbal. If was 'which' of example (14d) referred to a fact or an event, Otto would have given Karl a piggyback, which is certainly not the meaning of (14d).

Even if one restricted the antecedents of the $w h$-relative to propositional ones, $w h$-relatives are not only fact-related. In (15), for instance, the $w h$-relative is related to an attitude.

(15) Fred glaubte, dass Grass die Lesung abgesagt hatte, was Anna nicht Fred believed that Grass the reading cancelled had which Anna not gedacht hätte.

expect had

'Fred believed that Grass cancelled the reading, which Anna didn't expect.'

Finally, the examples in (16) show that so-called projective propositions, such as interrogative clauses or infinitival complements of modal verbs, can be appropriate antecedents of the $w h$-anaphor introducing a $w h$-relative clause.

(16) a. Maria will wissen, welche Prüfungen sie ablegen muss, was Maria wonders which exams she take must which sich Max ebenso fragte.

REFL Max as well wonders.

'Maria wonders which exams she has to take, which Max wonders, too.' 
b. Karl wollte eine Maus halten, was seine Mutter ihm aber nicht Karl wanted a mouse keep which his mother him PART not erlaubte.

allowed

'Karl wanted to keep a mouse, which his mother didn't allow.'

Thus, we have to conclude that a fact is one possible antecedent of the whanaphor, but not the only possible antecedent.

However, there is a semantic restriction that limits the class of admissible predicates and restricts the potential antecedents of the $w h$-anaphor. More precisely, the restriction given in (17) controls the wh-relative construction:

(17) In a $w h$-relative construction, the semantic type of the $w h$-anaphor must correspond to the semantic type of at least one entity that can be abstracted from the matrix clause.

Restriction (17) accounts for the fact that (18a) but not (18b) is ungrammatical. In both cases, the $w h$-anaphor is an argument of the verb glauben 'to believe' and therefore denotes a belief. An attitude, however, can be abstracted from the matrix clause only in (18b), but not in (18a).
a. * Fred heiratet Anna, was Max glaubt. Fred married Anna which Max believes.

b. Karl glaubt, dass Fred Anna heiratet, was Max auch Karl believes that Fred marries Anna which Max as well glaubt. believes

'Karl believes that Fred marries Anna, which Max believes, too.'

Adapting the DRT-based theory of Asher (1993), we can account for these facts by analyzing the semantic relation between the wh-relative and its matrix clause as an anaphoric relation established between the wh-anaphor and an entity abstracted from the matrix clause. Thereby it is assumed that the $w h$-anaphor introduces into the representation a discourse referent that needs to be characterized or resolved. The semantic type of this discourse referent is restricted by the predicate of the $w h$-relative in case the $w h$-anaphor is an argument of the relative clause's predicate. Otherwise it is propositional.

The discourse representations (K1) to (K3) illustrate the analysis for the ambiguous $w h$-construction (10), here repeated as (19).

(19) Die Geologen erforschen einen neuen Vulkan, was sehr interessant the geologists explore a new volcano which very interesting ist.

is

'The geologists explore a new volcano, which is very interesting.' 
Regarding the semantic relation between the $w h$-relative clause and the matrix clause, we can conclude that a $w h$-relative construction is grammatical if at least one suitable antecedent for the discourse referent introduced by the leftperipheral $w h$-anaphor can be found in the matrix clause. If the matrix clause contains several entities that can act as an antecedent of the $w h$-anaphor, a $w h$ construction is ambiguous.

Next, we will discuss how $w h$-relatives are syntactically related to their matrix clause.

\section{Complex Sentence Structure}

With regard to the syntactic relation, it becomes apparent that a wh-relative is not licensed by the predicate of the matrix clause. ${ }^{2}$ The $w h$-relative neither saturates one of the argument positions of the matrix predicate nor modifies the matrix predicate. Nevertheless, it is obvious that $w h$-relatives are dependent clauses.

Reis (1997) argues that there are certain clauses in German that are linked to the complex sentence structure without being part of the verbal projection of the matrix clause. Reis calls these clauses 'non-integrated', and she lists four main properties of this clausal class.

Firstly, a non-integrated clause is syntactically dispensable. Secondly, nonintegrated clauses are prosodically and pragmatically independent of the matrix clause, which is indicated by an independent focus domain. Thirdly, variable binding is not allowed from the matrix clause into the non-integrated clause; and fourthly, a non-integrated clause always occurs at the end of a complex sentence.

By applying these criteria to the $w h$-relatives it can be shown that $w h$ relatives are in fact typical non-integrated clauses.

\subsection{Root Clause Properties}

According to the first criterion, $w h$-relatives are syntactically unnecessary, since they behave like root clauses. This is supported by examples (20) - (22), which illustrate phenomena symptomatic of root clauses. (i) A wh-relative clause can easily be transformed into a main clause, as shown in (20). (ii) It can contain epistemic expressions, performative indicators, modal particles and so on, as shown in (21). (iii) It is not possible to form a yes/no-question integrating the whole $w h$-relative construction, as shown in (22).

\footnotetext{
${ }^{2}$ This can be shown by applying the traditional constituent tests, which clearly reveal that a wh-relative is neither attached to a verb nor a verbal phrase of the matrix clause, cf. Holler (2001).
} 
(20) Anna hat die Schachpartie gewonnen. Das ärgerte Peter. 'Anna won the game of chess. This annoyed Peter'.

(21) a. Anna hat die Schachpartie gewonnen, was Peter sicher Anna has the game of chess won which Peter certainly ärgerte. annoyed

'Anna won the game of chess, which must have annoyed Peter.'

b. Die Firma handelt mit Waffen, weshalb ich hiermit the company deals with weapons that's why I hereby kündige. hand in my notice

'The company deals with weapons, and that's why I hereby hand in my notice.'

c. Max hat den Preis bekommen, was wohl jeden überraschte. Max has the prize won which well everyone surprised

'Max won the prize, which was probably surprising for everyone.'

(22) * Hat Anna die Schachpartie gewonnen, was Peter ärgerte? has Anna the game of chess won which Peter annoyed

Thus, regarding the first criterion, wh-relatives clearly behave like nonintegrated clauses.

\subsection{Independent Focus Domain}

The second criterion for non-integrated clauses is that they are prosodically and pragmatically independent from the matrix clause and, thus, establish an independent focus domain.

The standard test for focus assumes that the focus structure of a given declarative utterance can be identified by reconstructing a question that would license the utterance as a coherent answer. The focus corresponds to the interrogative constituent in that question. Based on these test conditions, (23) suggests that the focus does not project out of the $w h$-relative, since (23a) is not a coherent answer to the question 'What happened?'.3

\footnotetext{
${ }^{3}$ In the example, focus is marked by a syntactic focus feature that projects from the pitchaccented focus exponent written in capital letters.
} 
(23) Was ist passiert?

a. \# [Anna gewann die Schachpartie, was Peter von seiner Anna won the game of chess which Peter from his SCHWEster erwartet hat. $]_{F}$ sister expected has

'Anna won the game of chess, which Peter expected from his sister.'

The independent focus domain of a $w h$-relative is also supported by (24), which demonstrates that the focus sensitive particle nur 'only' occurring in the matrix clause does not scope over the $w h$-relative:

(24) ? Anna gewann nur die Schachpartie, was Peter von seiner Anna won only the game of chess which Peter from his Schwester erwartet hat. sister expectedhas

'Anna only won the game of chess, which Peter expected from his sister.'

The observation that a $w h$-relative establishes an independent focus domain within the $w h$-relative construction provides additional evidence for the nonintegratedness of a $w h$-relative clause.

\subsection{No Quantification into a $W h$-relative}

The third of Reis's criteria applies to wh-relatives as well. A quantifier occurring in the matrix clause cannot bind a variable within the $w h$-relative. This is confirmed by (25).

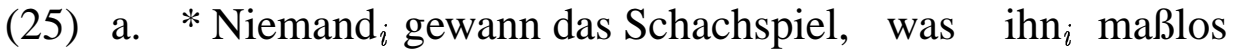
nobody $_{i}$ won the game of chess which him hextremely $^{2}$ ärgerte.

annoyed

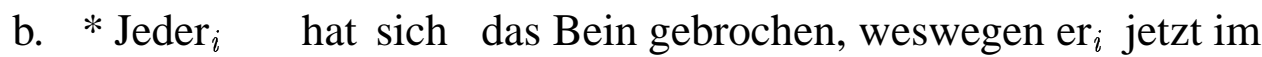
everyone $_{i}$ has REFL the leg broken that's why he ${ }_{i}$ now in Krankenhaus ist. hospital is

\subsection{Clause-final Position}

Last but not least, the fourth criterion for non-integrated clauses is also met by $w h$-relatives. (26) and (27) illustrate the observation that a $w h$-relative always comes last because it has to follow an extraposed complement clause (26) or relative clause (27). 
(26) a. Es fiel Maria nicht auf, dass sie sich verrechnet hatte, EXPL realized Maria not PART that she REFL mistaken had weswegen sie sich jetzt ärgert.

that's why she REFL now annoyed

'Maria didn't realize that she made a mistake, and that's why she is annoyed now.'

b. * Es fiel Maria nicht auf, weswegen sie sich jetzt

EXPL realized Maria not PART that's why she REFL now

ärgerte, dass sie sich verrechnet hatte.

annoyed that she REFL mistaken had

(27) a. Anna hat einen Ring verloren, der sehr wertvoll war, weshalb

Anna has a ring lost that very valuable was that's why

sie sich jetzt maßlos ärgerte.

she REFL now extremely annoyed

'Anna lost a ring that was very valuable, and that's why she was annoyed now.'

b. * Anna hat einen Ring verloren, weshalb sie sich jetzt

Anna has a ring lost that's why she REFL now

maßlos ärgerte, der sehr wertvoll war.

extremely annnoyed that very valuable was

Taking these four criteria into account, we can conclude that $w h$-relatives can be classified as non-integrated clauses. As has been shown, they establish an independent focus domain; they are inaccessible for variable binding from outside; they are syntactically dispensable, as they can be transformed into a main clause; and they are placed at the end of a complex sentence.

We can account for these facts by analysing a $w h$-relative as a projection of a specific phonologically empty relativizer heading a non-integrated relative clause. The lexical specification of this relativizer leads to an analysis in which a $w h$-relative attaches to the sentential projection introduced by the respective matrix clause.

The last part of the paper concentrates on this analysis, which is couched in the framework of HPSG.

\section{HPSG Analysis}

The standard phrase-structural analysis of restrictive relative clauses in HPSG, going back to Pollard and Sag (1994), is based on the assumption that a relative clause is a projection of a phonologically empty relativizer. The lexical entry of this relativizer is given in (28). The relativizer is subcategorized for two 
complements: a phrase containing a relative constituent expressed by a nonempty REL value and a finite verbal projection which is slashed by this relative phrase. The SLASH dependency is bound off by the relativizer. The relative clause is attached to a preceding noun by an application of the HEAD-ADJUNCT schema triggered by the attribute MOD. Since the indices of the noun and the relative phrase are identified and their RESTRICTION values are unified, the relative clause is interpreted as a property.

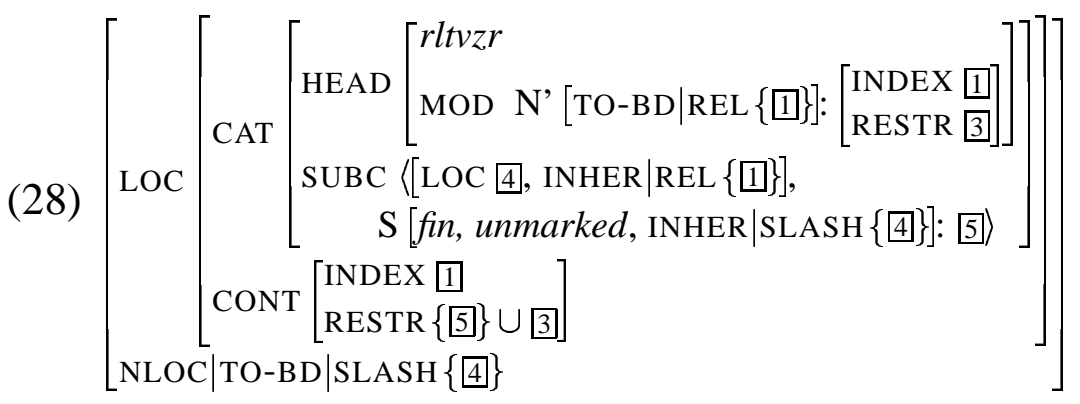

An analysis of the $w h$-relative construction has to account for at least two major properties of a $w h$-relative: (i) that it is a non-integrated clause; and (ii) that its syntactic antecedent may differ from its semantic one. Whereas the syntactic relation is always unique, as there is only one way a $w h$-relative is attached to its matrix clause, the semantic relation depends on the potential antecedents resolving the left-peripheral $w h$-anaphor.

To cope with these properties, a new relativizer is defined that serves as head of a non-integrated $w h$-relative clause. ${ }^{4}$ Similar to the restrictive relativizer, the newly defined relativizer takes two complements: a relative phrase and a finite verbal projection slashed by this phrase. It also bears a non-empty MODattribute. In contrast to the restrictive relativizer, however, the value of the MOD attribute is specified as FP, as indicated by the schematic analysis in (29). The wh-relative thus syntactically combines with a functionally complete and fully saturated sentential projection (i.e. FP) and not - as in the restrictive case - with a nominal phrase. ${ }^{5}$ (29) cover the semantic relation between the $w h$-relative and its antecedent I depart from the semantics used in standard HPSG. In line with Frank and Reyle (1995), the structure of the CONTENT attribute and the Semantics Principle are changed, thereby integrating aspects of the framework of DRT into the

\footnotetext{
${ }^{4}$ The proposed analysis could easily be restated in a construction-based setting, as in Sag (1997). We adhere to the phrase-structural account since i.a. it is not clear how the proliferation of types is prevented within a construction-based analysis. See Holler-Feldhaus (2001) for further arguments.

${ }^{5}$ Leaving the details of German sentence structure aside, we assume binary branching and the concept of functional completeness following Netter (1996). Functional completeness is expressed by a binary feature FCOMPL, which is specifi ed as 'plus' if a sentential head (e.g. a complementizer) has been realized and as 'minus' otherwise.
} 


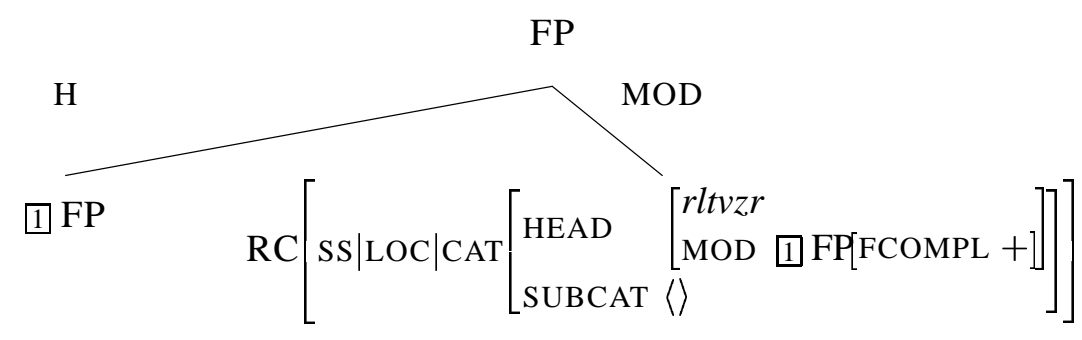

semantic component of HPSG. As one can see in (30), the CONTENT attribute is replaced by a complex feature structure, called DRS, which consists of three attributes, LS, SUBORD and CONDS. CONDS is a set of labelled DRS conditions, SUBORD contains information about the hierarchical structure of a DRS and LS defines distinguished labels within this hierarchy. Additionally, it is assumed that the DRS conditions instantiating the CONDS value are represented by a set of objects of type $p\left(\right.$ artial_- $\left._{-}\right) d r s$.

(30) $\left[\begin{array}{ll}d r s & \\ \text { LS } & {\left[\begin{array}{ll}\text { L-MAX } & \mathbf{l}_{\text {max }} \\ \text { L-MIN } & \mathbf{l}_{\text {min }}\end{array}\right]} \\ \text { SUBORD } & \{\mathbf{L} \leq \mathbf{L}\} \\ \text { CONDS } & \text { set-of-pdrs }\end{array}\right]$

The Semantics Principle adapted from Frank and Reyle (1995) is depicted in (31). It controls the inheritance of the partial DRSs defined in the CONDS attributes of the daughters to the CONDS value of the phrase. The semantic conditions are always inherited from both daughters and therefore project to the uppermost sentential level.

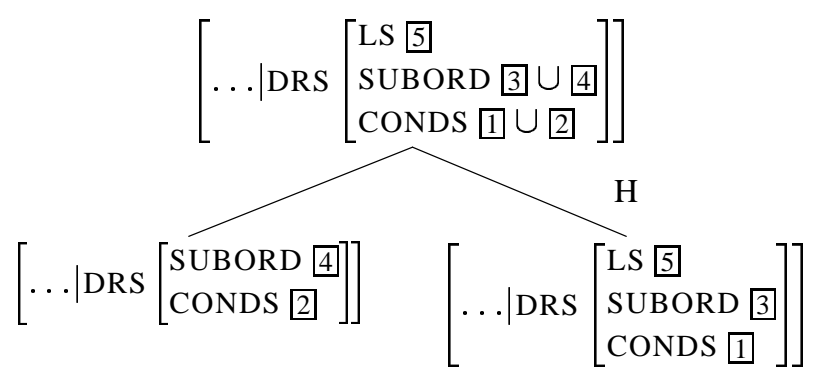

Moreover, an attribute DREF appropriate for objects of type pdrs that introduce a discourse referent is defined. The value of DREF is lexically instantiated. For instance, a verb introduces an event variable and a definite determiner an individual variable.

Given this theoretical framework, the semantic analysis sketched earlier can be implemented in HPSG. The $w h$-anaphor introduces a discourse referent by instantiating its DREF-attribute, and this discourse referent has to be related to 
an appropriate semantic object abstracted from the DRS of the matrix clause. This is ensured by a two-place function called abstr(act)-obj(ect), which takes the discourse referent of the $w h$-anaphor and the partial DRS of the matrix clause, and yields an abstract object appropriate to resolve the $w h$-anaphor.

This analysis is made possible by the SYNSEM value of the relativizer given in (32). In (32), the value of REL contains the d(iscourse_)ref(erent) of the wh-anaphor marked by tag 1 . Tag 2 represents the DRS conditions of the matrix clause whereas abstr-obj(1,2) represents the abstracted object which is the antecedent of the wh-anaphor's discourse referent.

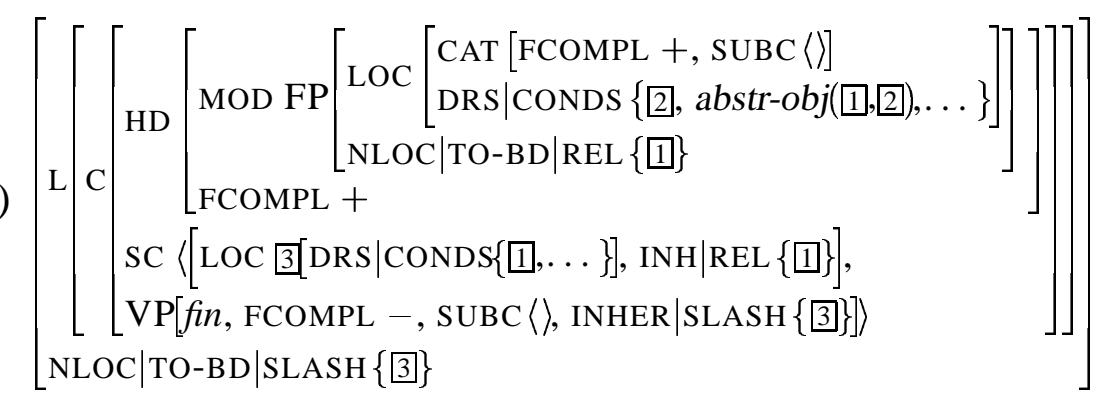

The simplified partial structure for the sentence Anna gewann die Schachpartie, was Peter ärgerte 'Anna won the game of chess, which annoyed Peter.' given in figure (33) illustrates the proposed analysis.

Ir(3) is example, the $w h$-relative clause $(=\mathrm{RP})$ is a projection of a functionally complete empty relativizer subcategorized for a fully saturated but functionally incomplete VP $(=11)$ and a relative phrase $(=[2)$. This relative clause is syntactically attached to a matrix clause that is functionally complete $\left(={ }_{5} \mathrm{FP}\right)$ by applying the HEAD-ADJUNCT Schema. The semantic relation between the matrix clause and the $w h$-relative is established by the anaphor was. According to the selection properties of the predicate ärgern 'to annoy', was 'which' introduces a propositional discourse referent $(=3)$ into the representation. This referent is resolved by an object (= abstr-obj (3, (3)) that is abstracted from the proposition introduced by the matrix clause $(=4)$.

\section{Conclusion}

By investigating the empirical properties of $w h$-relative clauses it was shown that they establish a class of German relative clauses of their own. Syntactically, they behave like typical non-integrated clauses and they are related to a functionally complete sentential projection. Semantically, however, wh-relatives can refer to entities of various semantic types, such as events, event-types or (projective) propositions. This grammatical behavior clearly can be attributed to the properties of the left periphery of a $w h$-relative clause. To account for the 


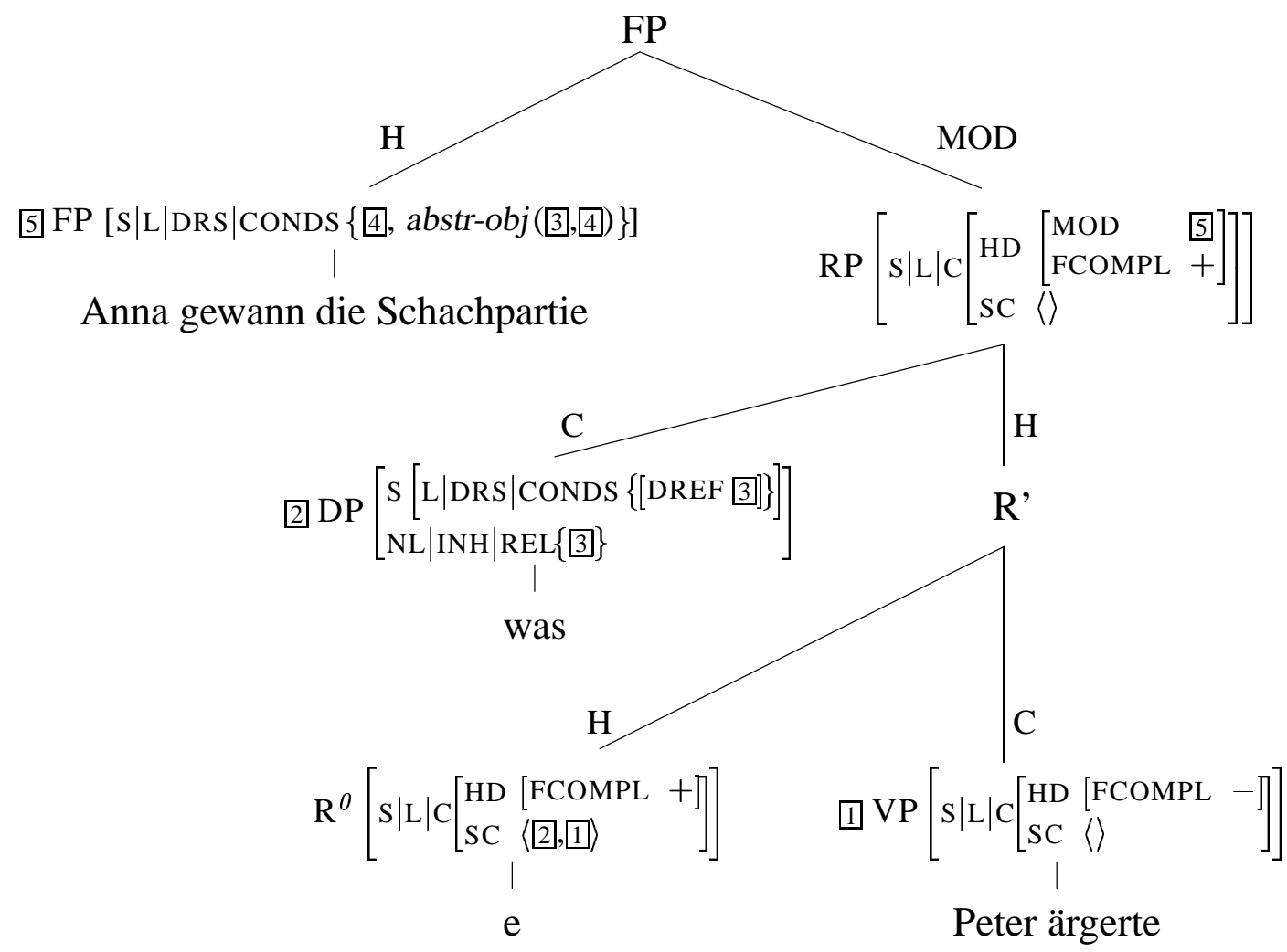

facts presented an HPSG analysis was developed that copes with $w h$-relative clauses. This analysis is based on the lexical properties of two left-peripheral elements: a $w h$-anaphor and a phonologically empty relativizer.

\section{References}

Asher, Nicholas. 1993. Reference to Abstract Objects in Discourse. Studies in Linguistics and Philosophy 50, Kluwer, Dordrecht.

Bech, Gunnar. 1957. Studien über das deutsche Verbum Infi nitum. Munksgaard, Kopenhagen, unver"and. Auflage 1983, Niemeyer, Tüubingen.

Brandt, Margareta. 1990. Weiterführende Nebensätze. Almquist \& Wiksell International, Stockholm.

Frank, Annette and Uwe Reyle. 1995. Principle Based Semantics for HPSG. In Proceedings of the 7th Conference of the EACL, March 27-31, Dublin, pp. 9-16.

Helbig, Gerhard. 1980. Was sind weiterf uhrende Nebens"atze? Deutsch als Fremdsprache, 17: 13-23.

Holler, Anke. 2001. Empirische und theoretische Aspekte der Grammatik der weiterf uhrenden Relativs ätze. Ph.D. diss., University of Tüubingen.

Holler-Feldhaus, Anke. 2001. An HPSG Analysis of German Wh-Interrogatives. In Tibor Kiss and Detmar Meurers, eds., Constraint-Based Approaches to Germanic Syntax, CSLI, Stanford, pp. 67-100.

Netter, Klaus. 1996. Functional Categories in an HPSG for German. Ph.D. diss., Universit”at 
des Saarlandes, Saarbr ucken, Published 1998 in Saarbr ücken Dissertations in Computational Linguistics and Language Technology, Vol. 3.

Pollard, Carl and Ivan A. Sag. 1994. Head-Driven Phrase Structure Grammar. CSLI and University of Chicago Press, Chicago.

Reis, Marga. 1997. Zum syntaktischen Status unselbst”andiger Verbzweit-S atze. In Christa Dürscheid, Karl Heinz Ramers, and Monika Schwarz, eds., Syntax im Fokus: Festschrift für Heinz Vater, Niemeyer, T"ubingen.

Sag, Ivan A. 1997. English Relative Clause Constructions. Journal of Linguistics, 33: 431484.

Steube, Anita. 1991. w-W"orter als Konnektoren in den sog. weiterf ürenden Nebens"atzen der deutschen Gegenwartssprache. In Marga Reis and Inger Rosengren, eds., Fragesätze und Fragen, Niemeyer, T’ubingen, pp. 95-111. 